\title{
Ensaios para Internação Domiciliar nos Dias Atuais.
}

\author{
Ribeiro, Bárbara Andréa; Zorzi, Cínthia Rozim; Prearo, Antonio Donizetti; \\ Santos, Roberta da Silva \\ Centro de Atenção Integral à Saúde — barbaraandrea@uol.com.br
}

INTRODUÇÃO a sugestão da internação domiciliar foi utilizada como uma estratégia de proteção e escolha compartilhada com o paciente e seu familiar, como base para o início do tratamento do Transtorno Mental e Comportamental devido ao uso de Substâncias Psicoativas em questão. OBJETIVOS - Proporcionar possibilidade da ressignificação do conceito de sua casa como ambiente protetor; - Implementar uma alternativa de cuidado junto à família com resgate de valores na dinâmica familiar. METODOLOGIA Contratamos com a família os atendimentos diários e na modalidade intensiva no CAPS AD. Esta abordagem foi a mais adequada para as características encontradas no usuário de maconha com complicação clínica diagnosticada como tromboangeíte obliterante no membro inferior direito, ocasionada pelo uso em grande quantidade da maconha (skunk e hidropônica) que possui um teor de THC até $20 \%$ acima das outras espécies. o papel de sua genitora foi utilizado como a representação do "cuidador", segundo as Diretrizes do Ministério da Saúde no que se refere ao Serviço de Atendimento Domiciliar (1). no acolhimento inicial foi observada a necessidade do fortalecimento da díade mãe e filho fragilizado pelo rompimento da confiança e das regras de convivência que a farmacodependência acarreta, necessitando de um fortalecimento para a evolução e manutenção do tratamento. RESULTADOS Foram evidenciados os pontos de risco e pontos de proteção tanto para a reaproximação familiar na busca do fortalecimento dos vínculos da díade, como para a prevenção de recaída do paciente. na terapêutica utilizada foram ofertados: uso dos medicamentos, atendimentos de referência, oficinas terapêuticas, atendimento psicoterápico individual, grupos pré-contemplativos, grupo familiar e a disponibilidade da equipe no atendimento pontual caso houvesse mecanismos ansiogênicos CONCLUSÕES As dificuldades encontradas estão relacionadas às negações de que a farmacodependência é uma doença ("eu consigo parar sozinho", "sou mais forte que a droga"), a crença de que a internação hospitalar tradicional é a única terapêutica (primeiro objetivo abordado quando no acolhimento) e a estigmatização da dúvida da eficiência dos equipamentos de saúde alternativos do SUS ("será que as coisas do SUS dão certo?"). Os facilitadores foram o trabalho em equipe multidisciplinar, a organização do equipamento de saúde, as ofertas das terapêuticas, o apoio familiar e, acima de tudo, o empenho e a disponibilidade do paciente na manutenção de seu tratamento como ressignificação de sua vida. REFERÊNCIAS 1- BRASIL. Ministério da Saúde. Portaria n.963, 27 de maio de 2013. 2- Projeto Terapêutico Institucional do Centro de Atenção Psicossocial Álcool e Drogas - CAPS/AD do Centro de Atenção Integral à Saúde de Santa Rita do Passa Quatro - SP. 3- GENTIL,V. Uso da Maconha e Psicose. In: BRASIL,M.A.A.; BOTEGA,N.J.; HETEM,L.A.B. (Eds.). PEC: Programa de Educação Continuada - Título de Especialista em Psiquiatria - Provas 2006-2007 - ABP. Rio de Janeiro:Guanabara Koogan S.A. p.240 - 252. 4- JUNGERMAN, F.S.; LARANJEIRA, R. et al. Maconha: qual a amplitude de seus prejuízos?. Revista Brasileira de psiquiatria, 2005; 27 (1): 5 - 6. 5- JUNGERMAN, F.S.; ZANELATTO, N.A.; Tratamento psicológico do usuário de maconha e seus familiares. São Paulo: Roca LTDA, 2007. 1a Edição.

Ribeiro, Bárbara Andréa; Zorzi, Cínthia Rozim; Prearo, Antonio Donizetti; Santos, Roberta da Silva. Ensaios para Internação Domiciliar nos Dias Atuais.. In: Anais do Congresso Internacional de Humanidades \& Humanização em Saúde [= Blucher Medical Proceedings, num.2, vol.1]. São Paulo: Editora Blucher, 2014. ISSN 2357-7282

DOI 10.5151/medpro-cihhs-10711 